\title{
Comparando Transparência Passiva na esfera estadual: Executivo, Legislativo e Judiciário
}

\author{
Comparing Passive Transparency in the Brazilian state level: Executive, Legislative and \\ Judicial
}

\author{
Amanda Finck Drehmer \\ Universidade do Estado de Santa Catarina - UDESC \\ amandadrehmer@gmail.com \\ Fabiano Maury Raupp \\ Universidade do Estado de Santa Catarina - UDESC \\ fabianoraupp@hotmail.com
}

\begin{abstract}
Resumo
O presente artigo compara no nível de transparência passiva os órgãos representantes dos três poderes do nível estadual (governo estadual, assembleias legislativas e tribunais de justiça). Além da avaliação das plataformas oferecidas pelas entidades analisadas para o cidadão colocar seu pedido de informação. Adicionalmente, foi enviada solicitação de informação foi encaminhada aos três poderes nos diversos estados da federação. Dos três poderes, os governos de estado foram os que apresentaram plataformas de acesso e-SIC mais desenvolvidas. Os resultados demonstram que os governos de estado estão mais avançados na transparência passiva em relação aos outros dois poderes. Contudo, de forma geral organizações dos três poderes no nível estadual possuem barreiras acesso a informações na transparência passiva e não atendem plenamente a legislação associada.
\end{abstract}

Palavras chave: Lei de acesso à informação. Transparência passiva. Setor público. Governos.

\begin{abstract}
The paper compares the executive, judicial and legislative branches from the several states in Brazil (state government, legislative council, courts of justice) on their transparency mechanisms. We evaluate the IT platforms offered by those public-sector entities to citizens run their requests for information. Additionally, we sent an specific requests for information to those entities. Comparing the three branches, executive entities (state governments) present the more develop platforms to request information. However, the organizations from the three branches at the state level in Brazil have platforms and processes which present a relevant type of barriers to citizens accomplish request of information as a form of passive transparency, and do not fully comply to transparency laws.
\end{abstract}

Keywords: Transparency Code. Passive transparency. Brazilian states. Public Sector.

\section{Introdução}

Escândalos políticos estão frequentemente presentes nos noticiários brasileiros, gerando uma sensação de impotência por parte da sociedade, que passa a olhar de modo cético os rumos que a política tem tomado no Brasil (FILGUEIRAS, 2009). A corrupção é apresentada por Pereira (2002) como um fenômeno que enfraquece a democracia, a confiança no Estado, a legitimidade dos governos e a moral pública, sendo um problema estrutural na sociedade e no sistema político brasileiro. $\mathrm{O}$ aparente aumento dos níveis de corrupção percebidos atualmente 
seria devido à uma maior dificuldade em esconder os desvios da administração pública no Brasil (SLOMSKI, 2012). O aumento da transparência aumentaria os riscos típicos da corrupção (VIEIRA; CALDAS, 2012).

Um dos tipos de transparência é a chamada "passiva", em que o Estado concede aos cidadãos acesso oportuno à informação que esteja em poder dos órgãos públicos, quando solicitada por eles. A exceção a essa obrigação se dá para os casos em há uma razão legalmente estabelecida para manter a informação em segredo, como nos casos que envolverem segurança nacional, direito de terceiros, procedimentos em trâmite cuja revelação antecipada prejudique o cumprimento de uma função pública, entre outros. Mesmo assim, deverá a lei assegurar aos cidadãos o direito de questionarem judicialmente a negativa de acesso (YAZIGI, 1999).

Para que haja transparência devem ser disponibilizadas não só as informações previstas legalmente, mas qualquer informação de interesse do cidadão. A transparência passiva, segundo a Lei de Acesso à Informação (LAI), garante aos cidadãos o acesso à informações que não são ativamente disponibilizadas pelos órgãos e entidades públicas. O que auxiliaria o acompanhamento e controle da atuação dos governantes.

$\mathrm{Na}$ literatura nacional, no nosso melhor esforço, encontramos apenas cinco trabalhos tratando o tema de transparência passiva, sendo que dois são da área da robótica ${ }^{1}$. Com o intento de contribuir com a temática, analisamos aqui em que grau as organizações dos governos de estado, dos tribunais de justiça e assembleias legislativas dos diferentes estados brasileiros cumprem os requisitos de transparência passiva, com a disponibilização de plataformas de solicitação de informações e célere e válida resposta às solicitações.

A LAI determina os procedimentos a serem adotados pelos órgãos públicos integrantes da administração direta, aplicável aos três poderes executivo, judiciário e legislativo (BRASIL, 2011). Contudo, o grau de atendimento à legislação pode ser diferente pelas organizações dos três poderes. $\mathrm{O}$ artigo oferece uma comparação entre organizações dos três poderes, e para isso a análise foca no nível estadual. O objetivo é identificar diferenças ou semelhanças no avanço da adaptação de cada poder aos requisitos de cumprimento da transparência passiva.

A pesquisa analisou as plataformas de solicitação de informação (e-SIC) de organizações dos diversos estados (27 governos estaduais, 27 assembleias legislativas e 27 tribunais de justiça) observando as funcionalidades da plataforma e eventuais dificuldades na sua operação. Ainda, foram enviadas solicitações para informações para estas organizações e observado o tempo e a validade da resposta.

\section{Conceitos de Accountability}

Accountability é "a construção de mecanismos institucionais pelos quais os governantes são constrangidos a responder, ininterruptamente, por seus atos ou omissões perante os governados" (ABRUCIO; LOUREIRO,2004, p.1). Porém o entendimento do termo accountability, depende de um amadurecimento da democracia e da sociedade (CAMPOS, 1990). A accountability ocorreria pelo processo eleitoral, que garante o princípio da soberania popular; pelo controle institucional durante os mandatos, como o controle social, parlamentar, judicial e administrativo-procedimental; e pelas regras estatais intertemporais, em que se limita o poder governamental para garantir os direitos dos indivíduos e da coletividade. Para que ocorram as formas de accountability citadas, devem ser respeitadas certas condições, entre as quais se destacam a liberdade de expressão e de reunião, a possibilidade de se obter diversidade de informações e a transparência e fidedignidade das informações públicas (ABRUCIO; LOUREIRO, 2004).

Em 2009, quase 20 anos após a publicação de Campos (1990), questionando a distância

\footnotetext{
${ }^{1}$ Em levantamento nas bases de dados Scopus, Spell, EBSCO, Proquest e Science Direct, em 2016. A busca foi feita pelos termos "transparência passiva" ou "passive transparency" no título, resumo ou palavras-chave.
} 
da aplicação do termo accountability para o português, Pinho e Sacramento (2009) estenderam a discussão, destacando que não há como traduzir em um termo único, e que accountability envolve "responsabilidade (objetiva e subjetiva), controle, transparência, obrigação de prestar contas, justificativas para as ações que foram ou deixaram de ser empreendidas, premiação e/ou castigo" (PINHO; SACRAMENTO, 2009, p.1364).

O conceito de accountability também pode ser analisado das dimensões vertical e horizontal propostas em O'Donnel (1998). Na horizontal, agências estatais são capacitadas e têm o direito e o poder legal para realizar ações como supervisão a sanções legais e impeachment contra ações ou emissões de outros agentes ou agências do Estado que possam ser qualificadas como delituosas. Já na dimensão vertical, cidadãos avaliam e punem os governos pelo seu desempenho principalmente nas eleições. Para isso usariam informações sobre os governos e desempenho de políticas públicas, eleições livres e justas, reivindicações sociais que possam ser proferidas sem risco de coerção e com cobertura regular pela mídia. $\mathrm{O}$ voo seria um instrumento de sanção retrospectivo para "incentivar", positivamente ou negativamente, seu representante a não se desviar dos seus interesses (MARIA, 2010).

Apesar da extensa literatura no tema, a definição do conceito ainda carece de consenso quanto a seu significado e de uma clara delimitação teórica (CENEVIVA, 2006). Em Ceneviva (2006) accountability não diz respeito a um predicado dos sujeitos, mas um atributo do sistema político que se impõe aos agentes públicos. A seguir trazemos alguns autores nacionais para expor a abordagem adotada por eles.

Rocha (2013) confirma tal posição, e entende accountability como um processo de avaliação e responsabilização permanente dos agentes públicos em razão dos atos praticados, sendo essa responsabilização mediante algum tipo de sanção, como a aprovação ou reprovação dada pela sociedade ao comportamento do indivíduo. Akutsu e Pinho (2002, p.731) abordam o conceito de accountability em duas partes, "a primeira delega responsabilidade para que a segunda proceda à gestão dos recursos; ao mesmo tempo, gera a obrigação daquele que administra os recursos de prestar contas de sua gestão, demonstrando o bom uso desses recursos". A prestação de contas é o foco do entendimento de Oliveira, Carvalho e Corrêa (2013), que consideram que o termo accountability na administração pública tem a funcionalidade de exigir que os agentes públicos prestem contas à sociedade de forma tempestiva, transparente e inteligível.

Tal responsabilização das autoridades e das organizações públicas depende da incorporação de normas, regras e mecanismos para punir os agentes públicos (BARACCHINI, 2002), pois os cidadãos só poderão participar ativamente das decisões públicas quando tiverem informações públicas e prestações de contas confiáveis por parte dos governantes e auditadas pelos controles externo e interno dos órgãos públicos (AKUTSU; PINHO, 2002). Apesar do acesso à informação ser condição necessária para assegurar a responsabilização dos governantes e dos burocratas por seus atos e omissões no exercício do poder público (CENEVIVA; FARAH, 2012, p.1000), ela não é suficiente. Porém o acesso à informação, que leva à transparência, é o início do processo de accountability, como mostra a figura de Papenfub e Schaefer (2010 apud CAMPAGNONI et al., 2016). 


\section{Figura 1 - Passos (etapas) da accountability}

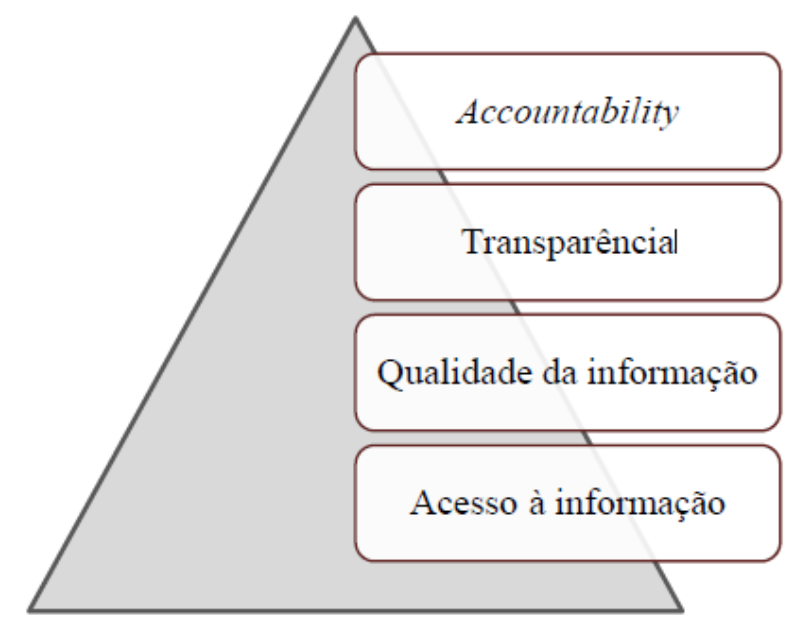

Fonte: elaborado por Campagnoni et al. (2016) com base em Papenfub e Schaefer (2010).

A garantia do acesso à informação, apresentada com qualidade (segundo passo), leva à transparência nas informações (terceiro passo), que promove a accountability (quarto passo) (PAPENFUB; SCHAEFER, 2010 apud CAMPAGNONI et al., 2016). Dessa forma, não existiria accountability sem transparência, qualidade da informação e acesso à informação (ROCHA, 2013), o que leva à necessidade de compreensão do processos de transparência em acesso à informação em si (ZUCCOLOTTO; TEIXEIRA; RICCIO, 2015).

\section{Conceitos de Transparência}

O conceito de transparência também está em construção (ZUCCOLOTTO; TEIXEIRA; RICCIO, 2015). Os autores mencionam uma relação triangular entre os conceitos de transparência, abertura e vigilância. Transparência é mais amplo que abertura (ZUCCOLOTTO; TEIXEIRA; RICCIO, 2015, p. 142) e que o princípio da publicidade (GUERRA, 2003). Enquanto publicidade garante a divulgação das ações governamentais, a transparência busca, além da divulgação, a compreensão do conteúdo pela sociedade.

Transparência vai além da oferta de informação, ou seja, da publicidade com acesso em múltiplos meios de baixo custo e domínio dos usuários, e envolve a compreensibilidade e a utilidade para decisões (PLATT NETO et al. (2007). A compreensibilidade está relacionada à apresentação visual, incluindo a formatação das informações e ao uso da linguagem. Para que as informações sejam facilmente entendidas devem ser simples, com linguagem acessível e orientada ao perfil dos usuários. Ainda, a relevância das informações disponibilizadas deve coincidir com os interesses dos usuários, na confiabilidade das informações a que os usuários têm acesso, ou seja, a garantia de veracidade do que é divulgado, e na comparabilidade, que deve ser propiciada entre períodos e entre entidades (PLATT NETO et al., 2007).

Michener e Bersch (2013) entendem que há duas condições necessárias para haver transparência: visibilidade e inferability. Para ser visível a informação deve ser razoavelmente completa e encontrada com facilidade. A completude está relacionada a um elevado grau de integridade e a facilidade de localização está relacionada à probabilidade de a informação ser encontrada. Já a inferability diz respeito à possibilidade de se coletarem inferências precisas a partir dos dados disponibilizados. Essa condição está diretamente relacionada à qualidade da informação, que deverá possuir três atributos: desagregação (dados não agregados, primários), verificação (informações validadas) e simplificação (informações compreensíveis).

Haverá transparência quando as informações forem localizadas de forma ágil e fácil e forem disponibilizadas em formato passível de verificação, linguagem clara e compreensível. Para que essas condições sejam asseguradas, faz-se necessário o estabelecimento de regras que 
orientem e sujeitem os órgãos públicos a seguir determinados padrões no fornecimento das informações. O avanço na legislação que trata do acesso às informações se constitui em um dos grandes propulsores para o aumento da transparência pública.

\section{Regulação Brasileira de Transparência}

$\mathrm{O}$ acesso às informações de atos praticados pela gestão pública está previsto na CRFB, como uma das questões a serem reguladas por lei para garantir a participação do usuário na administração pública direta e indireta. No artigo $5^{\circ}$, inciso XXXIII, a CRFB prevê o direito de acesso às informações: "todos têm direito a receber dos órgãos públicos informações de seu interesse particular, ou de interesse coletivo ou geral, que serão prestadas no prazo da lei, sob pena de responsabilidade, ressalvadas aquelas cujo sigilo seja imprescindível à segurança da sociedade e do Estado" (BRASIL, 1988).

Com a publicação da Lei no 12.527 em 18 de novembro de 2011, Lei de Acesso à Informação - LAI (BRASIL, 2011), o Brasil efetiva o direito de acesso previsto no artigo $5^{\circ}$ da CRFB. Dessa forma, consolida e define o marco regulatório sobre o acesso à informação pública sob a guarda do Estado; estabelece procedimentos para que a Administração responda a pedidos de informação do cidadão; e estabelece que o acesso à informação pública é a regra, e o sigilo, a exceção (CGU, 2011). Podem ser considerados os seguintes benefícios provenientes da adoção de uma lei de acesso à informação: "combate à corrupção, enfrentamento de abusos por parte de agentes governamentais não comprometidos com a democracia e o bem comum, defesa dos direitos humanos, eficiência na gestão pública, melhoria do debate público e reforço na participação cidadã" (ANGÉLICO; TEIXEIRA, 2012, p.9). Os autores entendem que a socialização das informações governamentais contribui para a efetividade dos mecanismos anticorrupção, através, por exemplo, das denúncias feitas pelas mídias e da pressão social para punição.

A Lei de Acesso à Informação está estruturada em seis capítulos e quarenta e sete artigos, os quais regulamentam quem são os órgãos e instituições que tem o dever de publicar, quais informações públicas devem ser disponibilizadas, qual o procedimento a ser adotado na requisição, processamento e disponibilização das informações requeridas diretamente pelos cidadãos, dentre outras disposições que se fazem necessárias para a efetivação do direito de acesso à informação e para a realização do controle pela sociedade (BRASIL, 2011; WARMLING; BERNARDES; SANTOS, 2014; ANGÉLICO, 2015).

As regras previstas na LAI aplicam-se a todos os órgãos públicos integrantes da administração direta dos poderes executivo, judiciário e legislativo e órgãos autônomos, assim como às autarquias, fundações públicas, empresas públicas, sociedades de economia mista e demais entidades controladas direta ou indiretamente pela União, Estados, Distrito Federal e Municípios. Os órgãos e entidades do poder público deverão assegurar: a gestão transparente da informação; a garantia de autenticidade, disponibilidade e integridade da informação; e a proteção da informação sigilosa e da informação pessoal (BRASIL, 2011).

\section{Trajetória Metodológica}

A pesquisa descritiva coletou documentos a partir da técnica da observação estruturada com um roteiro previamente estabelecido (FERREIRA; TORRECILHA; MACHADO, 2012). Em seguida, foi feita análise das respostas recebidas de um experimento (de transparência passiva) da solicitação de informação dos poderes estaduais. A coleta dos dados referente às plataformas ou seção dedicada à transparência ou à Lei de Acesso à Informação, bem como o envio dos pedidos se deu entre 08 e 29 de maio de 2017. O retorno dos poderes foi monitorado por dois meses após o envio do pedido. A taxa de retorno aos pedidos realizados foi de $100 \%$ nos governos de estado, $56 \%$ nos tribunais de justiça e $24 \%$ nas assembleias legislativa. Considerando a qualidade das respostas, como será tratado na análise, foram consideradas 
satisfatórias apenas 17 respostas dos governos de estado, 10 dos tribunais de justiça e 4 das assembleias legislativas.

Manter uma plataforma digital para realização da transparência passiva dos governos de estados, tribunais de justiça e assembleias legislativas, tem sido cada vez mais relevante, pois com o porte populacional faz com que o contato com os governantes, quando ocorre, seja mais digital do que presencial (RAUPP; PINHO, 2013). Na busca por informações que não estão disponíveis nos portais eletrônicos dos órgãos públicos, a experiência do cidadão pode ser dividida em dois momentos principais: o envio da solicitação de informação e o recebimento da informação. Assim, para investigar a transparência passiva dos poderes foi necessário avaliar (i) a plataforma em que a solicitação é realizada, e (ii) as respostas recebidas.

A investigação baseou-se nas metodologias desenvolvidas pelo Programa de Transparência Pública da FGV (PTP-FGV) (MICHENER; MONCAU; VELASCO, 2014; PADILHA; MICHENER; CONTRERAS, 2016) e pela organização não-governamental de direitos humanos "Artigo 19" (PAES; BALBINO; MARCHEZINI, 2014). Foram analisadas as plataformas de solicitação de informação (e-SIC) de organizações dos estados brasileiros (27 governos estaduais, 27 assembleias legislativas e 27 tribunais de justiça), incluindo o Distrito Federal, observando as funcionalidades da plataforma e eventuais dificuldades na sua operação.

O modelo de avaliação das plataformas foi elaborado por Padilha, Michener e Contreras (2016) para avaliar a aplicação da LAI nos governos de estado e grandes cidades. Michener, Moncau e Velasco (2014) utilizaram a taxa de resposta e o tempo de envio das respostas para avaliar a transparência dos executivos da União, Distrito Federal, São Paulo, Minas Gerais e Rio de Janeiro, bem como suas respectivas capitais. O Quadro 1 detalha o modelo de avaliação das plataformas.

Quadro 1 - Modelo de avaliação das plataformas

\begin{tabular}{|c|c|c|}
\hline Indicadores & Pontuação & Critérios \\
\hline \multirow{3}{*}{$\begin{array}{l}\text { Comunicação na } \\
\text { plataforma }\end{array}$} & 100 & $\begin{array}{l}\text { Plataforma possibilita enviar solicitação, receber respostas e } \\
\text { fazer apelações }\end{array}$ \\
\hline & 50 & $\begin{array}{l}\text { Plataforma proporciona enviar solicitação e receber resposta ou } \\
\text { espaço dedicado ao acesso à informação }\end{array}$ \\
\hline & 0 & $\begin{array}{l}\text { Não existe plataforma ou espaço dedicado ao acesso à } \\
\text { informação }\end{array}$ \\
\hline \multirow{3}{*}{ Login e Recibos } & 100 & $\begin{array}{l}\text { A plataforma que proporciona o envio de solicitações e o } \\
\text { recebimento de respostas tem um login específico }\end{array}$ \\
\hline & 50 & Fornece ou recibo ou protocolo do pedido \\
\hline & 0 & Não fornece nem recibo nem protocolo do pedido \\
\hline \multirow{3}{*}{$\begin{array}{l}\text { Barreiras para o } \\
\text { acesso }\end{array}$} & 100 & $\begin{array}{l}\text { Não possui limite de caracteres e não requer informações } \\
\text { pessoais em adição ao nome, CPF/RG e contato }\end{array}$ \\
\hline & 50 & $\begin{array}{l}\text { Não requer informações pessoais em adição ao nome, } \\
\text { CPF/RG e contato; porém impõe limite de caracteres }\end{array}$ \\
\hline & 0 & Requer informações pessoais além do nome, $\mathrm{CPF} / \mathrm{RG}$ e contato \\
\hline
\end{tabular}

Fonte: Elaborado com base em Padilha, Michener e Contreras (2016).

Na comunicação na plataforma foi avaliado se o sistema coloca em prática os processos relevantes para a transparência passiva, quais sejam, enviar solicitações, recursos e receber respostas. Assim, foram atribuídos: 100 pontos, se por meio da plataforma é possível enviar uma solicitação, receber respostas e fazer apelações; 50 pontos, se a plataforma proporciona a) enviar solicitação e receber resposta ou b) espaço dedicado para acesso à informação; e pontuação 0 , se não existir plataforma ou espaço dedicado ao acesso à informação (PADILHA; 


\section{MICHENER; CONTRERAS, 2016).}

Em relação à existência de login e recibos, foi avaliada a garantia de que será possível rastrear o andamento do processo e comprovar que o pedido foi realizado. Assim, foram atribuídos: 100 pontos, se a plataforma que proporciona o envio de solicitações e o recebimento de respostas tem um login específico; 50 pontos, se fornece ou recibo ou protocolo do pedido; e pontuação 0, se não fornece nem recibo nem protocolo do pedido. Entende-se por recibo a comprovação de que o pedido foi realizado e recebido pelo poder, já o protocolo trata-se de número que permite acompanhar o andamento da solicitação (PADILHA; MICHENER; CONTRERAS, 2016).

Quanto às barreiras para o acesso, foram avaliadas a existência de restrições ao pedido com limite de caracteres e a exigência de fornecer mais informações pessoais do que determinado por lei. Assim, foram atribuídos: 100 pontos, se o formulário não possui limite de caracteres e não requer informações pessoais em adição ao nome, $\mathrm{CPF} / \mathrm{RG}$ e contato; 50 pontos, se não requer informações pessoais em adição ao nome, $C P F / R G$ e contato; porém impõe limite de caracteres; e pontuação 0 , se requer informações pessoais além do nome, $\mathrm{CPF} / \mathrm{RG}$ e contato, independente de impor ou não limite de caracteres (PADILHA; MICHENER; CONTRERAS, 2016).

Ainda, foram enviadas solicitações para informações para estas organizações e observado o tempo e a validade da resposta. A solicitação teve o mesmo teor para todos os poderes por se tratar de procedimento relacionado à LAI e comum a todos, tendo como objetivo buscar mais informações a respeito da implementação da LAI pelos poderes. Foi solicitado o número de pedidos de informação recebidos, respondidos e negados ao longo do ano de 2016, bem como as justificativas dadas para as rejeições. O conteúdo das respostas foi analisado com base no modelo desenvolvido por Paes, Balbino e Marchezini (2014) para avaliar a transparência dos três poderes no nível federal.

Algumas limitações foram identificadas no decorrer da pesquisa. A primeira foi a escassez de trabalhos acadêmicos sobre a temática abordada, e consequente dificuldade de comparações dos resultados. A segunda, nossos resultados se referem ao período da coleta de dados, não captando eventuais avanços e atualizações nas plataformas de transparência passiva. Terceira limitação, o modelo de avaliação das plataformas de Padilha, Michener e Contreras (2016), apesar de aplicável a todas as esferas e poderes, foi construído com base em pesquisas no poder executivo ou na esfera federal, ou seja, em órgãos que se encontram em estágio mais avançado de atendimento aos requisitos da LAI. Nesse contexto, convém analisar as barreiras encontradas nas plataformas ao se realizar um pedido de acesso à informação. Porém, quando se aplica o modelo aos judiciários e legislativos estaduais, a avaliação das dificuldades enfrentadas para realização do pedido não tem o mesmo efeito, uma vez que um formulário geral de contato não apresenta barreiras, mas também não é um espaço destinado ao acesso à informação. Nesses casos, a ausência de barreiras não é um mérito do poder, uma vez que ocorre pela simplicidade do espaço disponibilizado pelo poder.

\section{Resultados Empíricos na Transparência Passiva Comparada}

Os governos de estado possuem a plataforma de atendimento das solicitações mais estruturada comparando com assembleias legislativas e tribunais de justiça. O e-SIC é disponibilizado em todos os governos de estado, com as melhores notas de comunicação, existência de login e emissão de recibos. Os governos de estado foram o único poder respondeu todos os pedidos, apesar de com atraso em alguns casos. A Tabela 1 mostra um resumo da comparação, e o panorama geral pode ser visto na Tabela 2 (Apêndice). 
Tabela 1: Comparativo dos principais indicadores de cada poder

\begin{tabular}{c|c|c|c|c|c|c|c}
\hline Poderes & $\begin{array}{c}\text { Número } \\
\text { de organ. }\end{array}$ & $\begin{array}{c}\text { Comunicação na } \\
\text { plataforma } \\
\text { (média) }\end{array}$ & $\begin{array}{c}\text { Login e } \\
\text { Recibos } \\
(\text { média) }\end{array}$ & $\begin{array}{c}\text { Barreiras } \\
\text { (Média) }\end{array}$ & $\begin{array}{c}\text { Pedidos } \\
\text { Respondidos } \\
(\%)\end{array}$ & $\begin{array}{c}\text { Respostas } \\
\text { Satisfatórias } \\
(\%)\end{array}$ & $\begin{array}{c}\text { Tempo } \\
\text { médio } \\
(\text { dias })\end{array}$ \\
\hline Executivo & 27 & 74,1 & 81,5 & 57,4 & 100 & 68 & 10,5 \\
\hline Judiciário & 27 & 46,3 & 31,5 & 63,0 & 56 & 40 & 4,5 \\
\hline Legislativo & 27 & 40,7 & 29,6 & 63,0 & 24 & 16 & 10,5 \\
\hline
\end{tabular}

Fonte: Dados da pesquisa (2017).

A comparação dos indicadores permite observar diferenças no desempenho de cada poder. A maior parte dos estados analisados apresentou resultados melhores em seus executivos do que nos judiciários e legislativos, refletindo a heterogeneidade existente na transparência passiva dos poderes estaduais brasileiros.

\subsection{Governos de Estado: o Poder Executivo}

Manter plataformas bem estruturadas contribui para as melhores taxas de retorno. Os eSICs dos governos de estado permitem colocar o pedido de informação, acompanha-lo e receber retorno por e-mail ou na própria plataforma. Dessa forma facilita o controle do pedido pelo cidadão e o controle do próprio órgão sobre os pedidos recebidos que devem ser atendidos. Muitas plataformas também possibilitaram ao requerente fazer apelação caso não ficasse satisfeito com a resposta recebida.

O retorno das solicitações pode ser considerado rápido. Dentre os dez estados que responderam nos primeiros cinco dias decorridos da realização do pedido sete forneceram acesso integral aos dados solicitados. Por possuírem e-SIC, os órgãos têm os dados sobre os pedidos recebidos de forma sistematizada e, em muitos casos, já disponibilizam ativamente essa informação através de relatórios estatísticos. Sendo assim, a quantidade de pedidos recebidos, respondidos e negados, além de suas justificativas, são informações que podem ser rapidamente fornecidas, pois já estão contabilizadas e apresentadas através de gráficos e tabelas, de forma compreensível ao cidadão.

As plataformas e-SIC influenciam diretamente no desempenho dos poderes quanto à transparência passiva. Seu grande potencial como ferramenta anticorrupção reside particularmente em reforçar a eficácia do controle interno e gerencial sobre as ações de corrupção, promovendo a responsabilização e transparência (BERTOT; JAEGER; GRIMES, 2010). Por outro lado, os principais aspectos restritivos à transparência passiva observados nos governos de estado foram: presença de barreiras nas plataformas, declaração de ausência da informação solicitada e respostas incompletas. As barreiras nas plataformas incluem falha de tecnologia que impede completar o envio da solicitação (casos do Amapá e da Bahia), e que afetam a usabilidade (BERTOT; JAEGER; GRIMES, 2010).

Desde os primeiros momentos de vigência da LAI, a identificação do solicitante de informação foi um dos maiores obstáculos enfrentados. Alguns órgãos têm diferentes tratamentos de acordo com o tipo de requerente, principalmente jornalistas (PAES et al., 2017), contrariando a legislação (BRASIL, 2011). Além de descumprir a lei, a exigência de dados de identificação adicionais aos previstos pode contrariar a noção de impessoalidade, princípio básico da administração pública.

Alguns casos justificaram o não envio da solicitação pela ausência da informação solicitada (caso do Rio de Janeiro). Em alguns casos as solicitações são recebidas pelo e-SIC e encaminhadas para o órgão responsável, onde se perde o controle se as solicitações foram ou não atendidas, o que demandaria que uma Controladoria-Geral ou Ouvidoria coordenassem se as solicitações foram atendidas. Na realidade municipal e estadual os dados ficam dispersos, cada órgão trata dos pedidos e documentos diretamente recebidos pelo órgão, e não todos 
aqueles contabilizados por outros órgãos do estado ou município (PAES et al., 2017). Ficam prejudicadas as tentativas de centralizar a aplicação da LAI, dificultando o monitoramento da lei e o acesso à informação por parte do cidadão (PAES et al., 2017).

Apesar dos aspectos mencionados, os governos de estado tiveram significa quantidade de respostas incompletas (como em Sergipe e Roraima). Os estados mencionados responderam no prazo determinado pela LAI, não entregaram apenas de parte da informação solicitada. Em contrapartida, Paraíba e Pernambuco receberam nota máxima quanto à plataforma e por fornecerem acesso integral e satisfatório aos dados solicitados, sendo considerados exemplos no exercício da transparência passiva. Apesar da necessidade de alguns ajustes, como a redução das barreiras nas plataformas e a melhoria na qualidade das respostas, os governos de estado, de modo geral, podem ser considerados transparentes na forma passiva.

\subsection{Tribunais de Justiça: o Poder Judiciário}

Os tribunais de justiça foram os mais heterogêneos dos três poderes, apresentando ao mesmo tempo estados em níveis mais avançados de transparência passiva e outros em estágios iniciais. Dentre os tribunais de justiça que forneceram acesso integral e satisfatório e também apresentaram uma boa estrutura em suas plataformas estão Sergipe, Santa Catarina e Amapá. O Tribunal de Justiça do Sergipe demonstrou estar consciente da importância de fornecer ao cidadão uma informação compreensível e enviou, além dos dados solicitados, uma explicação da forma como o poder classifica um pedido de informação.

Os estados do Distrito Federal, Roraima, Mato Grosso do Sul e Pará foram os que apresentaram os piores desempenhos em relação à transparência passiva. Nos dois primeiros foram encontradas barreiras tecnológicas, que impediram o envio dos pedidos, ou seja, plataformas distantes do objetivo de estimular maior interação e transparência entre sociedade e governo, e de ampliar o espaço para o exercício da cidadania e da prática democrática (JAMBEIRO et al., 2011). Já os tribunais de justiça do Mato Grosso do Sul e Pará não apresentaram em seus sítios eletrônicos nenhum espaço destinado ao acesso à informação, sendo os pedidos realizados em formulário geral de contato, para os quais não se obteve resposta. Esse espaço não é considerado adequado para o recebimento de solicitações de acesso à informação.

Os principais aspectos restritivos à transparência passiva observados nos tribunais de justiça foram: não recebimento de protocolo ou recibo do envio do pedido, ausência de resposta e negativa de acesso à informação. A maioria dos tribunais de justiça não apresentaram login de acesso e emissão de recibos, e também não responderam ao pedido. Ao não fornecer ao cidadão uma comprovação de que recebeu o pedido, o cidadão não tem como cobrar a resposta, e o próprio poder terá dificuldade para controlar as solicitações recebidas.

$\mathrm{O}$ acesso à informação foi negado pelos tribunais de justiça do Rio de Janeiro, Ceará e Alagoas, justificados pela interpretação do pedido como genérico ou que exigiria trabalhos adicionais. As negativas de acesso a dados poderiam ocorrer em casos de pedidos genéricos; desproporcionais ou desarrazoados; ou exigirem trabalhos adicionais de análise, interpretação ou consolidação de dados e informações (BRASIL, 2012). No caso de Ceará e Alagoas, solicitaram que o pedido fosse esclarecido. Já o Tribunal de Justiça do Rio de Janeiro alegou que, como ainda não possui sistema informatizado, para responder ao pedido teria que fazer manualmente a análise e classificação dos 137 pedidos recebidos em 2016.

Situações como essas são vistas com preocupação, pois demonstram que os poderes ainda esbarram em dificuldades básicas para o exercício da transparência passiva, como o desconhecimento das exigências da LAI e a falta de recursos tecnológicos. A simplicidade do pedido realizado é ainda um fator agravante, considerando que as informações solicitadas já deveriam estar sistematizadas e disponíveis nos portais para amplo acesso.

O indeferimento do pedido com base em interpretação ampla da cláusula de trabalho 
extra foi uma das barreiras identificadas por Michener, Moncau e Velasco (2014) em avaliação da transparência passiva realizada com alguns estados e municípios brasileiros em 2014. Na ocasião, vários órgãos fizeram uso desta disposição de forma excessivamente ampla, indeferindo pedidos legítimos e violando a LAI. Segundo os autores, todo pedido de acesso à informação gerará algum grau de trabalho adicional ao órgão que o recebeu, principalmente nos casos em que se trata de informação que não foi previamente consolidada. Mesmo que a informação solicitada verse sobre temas básicos para uma gestão pública eficiente, é comum que não tenha sido previamente produzida (MICHENER; MONCAU; VELASCO, 2014).

O cenário observado indica que a maior parte dos tribunais de justiça não está, ou justifica não estar, preparado para responder as perguntas de acesso à informação. $\mathrm{O}$ que o coloca em uma condição de descumprimento da transparência passiva (YAZIGI, 1999). Para diminuir a incidência de casos de utilização indevida da cláusula de trabalho adicional ou de pedidos genéricos, é primordial que os poderes implementem sistemas de gestão de informação para armazenar e sistematizar os dados por eles gerados e utilizados.

\subsection{Assembleias Legislativas: o Poder Legislativo}

As assembleias legislativas apresentaram a pior taxa de retorno dentre os três poderes, com apenas cinco respostas dentro do prazo legal. Ainda, dessas respostas, duas tem resposta questionável. A Assembleia Legislativa do Rio Grande do Sul primeiramente enviou e-mail solicitando via digitalizada do RG do requerente, cujo número já havia sido informado na realização do pedido. A exigência da digitalização do documento demanda informações pessoais adicionais, como nome dos pais, local de nascimento e foto, pode ser interpretado como dificultador ao acesso à informação pelo cidadão. Cabe destacar que o $\$ 1^{\mathrm{o}}$ da LAI estabelece que a identificação do requerente não pode conter exigências que inviabilizem a solicitação (BRASIL, 2011). Mesmo a digitalização do documento não tendo sido disponibilizada, a Assembleia Legislativa do Rio Grande do Sul enviou a resposta ao pedido de informação. Porém, a forma como a informação foi disponibilizada não permitiu compreender quantos pedidos haviam sido recebidos, respondidos e negados no ano de 2016. Dessa maneira, a resposta fornecida não atendeu ao elemento compreensibilidade definido por Platt Neto et al. (2007) como um dos elementos que constituem a transparência pública e relaciona-se à apresentação visual, incluindo a formatação das informações e ao uso da linguagem.

Já a Assembleia Legislativa do Rio de Janeiro negou o acesso à informação por entender que a mesma já está disponível no Diário Oficial ou sítio eletrônico da Assembleia legislativa. No entanto, não houve indicação de lugar e forma para acesso à informação, conforme estabelecido pela LAI para as ocasiões em que a informação já está disponível ao público. Ser transparente é também facilitar o acesso à informação e disponibilizá-la de forma que seja de fácil localização (PLATT NETO et al., 2007).

O não fornecimento de informações já disponíveis em transparência ativa é também retratado por Michener, Moncau e Velasco (2014). Na pesquisa realizada pelos autores, algumas respostas recebidas não indicavam de forma clara o local exato onde o cidadão poderia encontrar a informação, fornecendo apenas o endereço genérico do portal eletrônico, ou então disponibilizavam as informações em formato diferente do solicitado, como forma de eximir o órgão de responder o pedido.

Os principais aspectos restritivos à transparência passiva observados nas assembleias legislativas foram: inexistência de espaço destinado ao acesso à informação nos portais eletrônicos, não recebimento de protocolo ou recibo do envio do pedido e ausência de resposta. Os portais eletrônicos de 7 assembleias legislativas estaduais não apresentavam espaço destinado ao acesso à informação. O portal da Assembleia Legislativa do Sergipe não disponibilizava possibilidade de comunicação eletrônica com o cidadão, nem mesmo um e-mail geral de contato. Além de descumprir o artigo $10 \S 2^{\circ}$ da LAI, por não viabilizarem alternativa 
de encaminhamento de pedidos de acesso por meio de seus sítios oficiais na internet, nenhuma das 7 assembleias legislativas deram retorno ao pedido realizado.

O cenário encontrado nas Assembleias Legislativas mostra uma relação direta entre a plataforma disponível e o retorno do poder. As duas assembleias legislativas que demonstram máxima transparência, disponibilizam e-SIC e responderam dentro do prazo previsto na LAI. Além disso, as cinco respostas recebidas das assembleias legislativas foram de estados que possuíam e-SIC ou formulário para pedido de informação, o que reforça a importância dos sistemas eletrônicos nos portais dos poderes para que a transparência passiva ocorra.

A mesma relação também pode ser estabelecida entre a ausência de resposta e o não recebimento de protocolo ou recibo do envio do pedido. Das 15 assembleias legislativas estaduais que não forneceram nenhum comprovante de envio do pedido, apenas 2 responderam. A ausência de protocolo ou recibo já demonstra a falta de controle do poder sobre os pedidos recebidos. As assembleias legislativas estaduais não apresentam canais eficientes de comunicação entre governo e sociedade (CGU, 2011). Em contrapartida, as assembleias do Distrito Federal, Espírito Santo e Pernambuco foram os que apresentaram melhor desempenho no exercício da transparência passiva, disponibilizando espaço para solicitação de informação e fornecendo resposta integral e satisfatória.

As barreiras encontradas nas assembleias legislativas demonstram sua incipiência frente aos demais poderes. Os problemas identificados não estão relacionados à qualidade da resposta e sim à sua ausência ou, ainda pior, omissão na disponibilização de espaço para envio do pedido. Essas restrições demonstram que as assembleias estão em uma fase inicial da implementação da LAI, sendo dos três poderes, o menos transparente na forma passiva.

\section{Discussões}

$\mathrm{Na}$ análise da transparência passiva nos poderes estaduais brasileiros (governos de estados, tribunais de justiça e assembleias legislativas) ficou evidente a heterogeneidade, pois cada um dos três poderes comportou-se de forma distinta em relação tanto ao espaço destinado às solicitações de informação quanto ao retorno dado aos pedidos. O Estado da Bahia demonstrou estar tendo dificuldades em adequar-se aos requisitos básicos de transparência passiva, pois tanto no governo de estado quanto na assembleia legislativa não foi possível completar o envio do pedido de informação, além disso, no tribunal de justiça não houve retorno.

A atuação da CGU no poder executivo é um dos fatores que pode estar influenciando no melhor desempenho desse poder frente aos demais. O Ministério da Transparência e Controladoria-Geral da União (CGU), órgão responsável pela transparência e combate à corrupção, conduz a implementação da LAI nos órgãos do executivo federal. Buscando promove-la além do âmbito do executivo federal, também avalia a transparência pública em estados e municípios brasileiros. Esse acompanhamento periódico do desempenho dos executivos estaduais estimula $o$ aprimoramento da transparência passiva. $O$ trabalho desempenhado pela CGU representa os mecanismos de controle e fiscalização do poder público citados por Ceneviva e Farah (2012) como necessários para assegurar a responsabilização dos governantes e dos burocratas por seus atos e omissões no exercício do poder público.

Através do programa Brasil Transparente, a CGU também auxilia estados e municípios a se adequarem às medidas de governo transparente previstas na LAI. A CGU disponibiliza a relação dos órgãos que aderiram ao programa até junho de 2017. No nível estadual, é possível observar a adesão de 13 governos de estado, 3 assembleias legislativas e nenhum tribunal de justiça. Dos 13 executivos que participam do programa, 10 forneceram resposta satisfatória ao pedido de informação, representando um percentual de $77 \%$. Se forem considerados os outros 14 poderes executivos que não aderiram ao programa, o percentual dos que forneceram respostas satisfatórias cai para 50\%. Os 3 legislativos participantes são Rio Grande do Sul, 
Distrito Federal e Espírito Santo, todos eles responderam à solicitação de informação. Apesar de serem apenas três, o fato de todos terem respondido pode ser considerado um retorno expressivo dado que no legislativo apenas $24 \%$ forneceram resposta ao pedido de informação. Os dados demonstram a importância da atuação da CGU e o potencial de melhoria da transparência passiva com a adesão ao programa.

$\mathrm{Na}$ esfera federal, Paes et al. (2017) apontam que os órgãos mais transparentes são do poder executivo, âmbito de atuação da CGU. A falta de um órgão autônomo destinado a promover e garantir o acesso à informação em todos os níveis e esferas de governo resulta na heterogeneidade da aplicação da lei. Para suprir essa ausência, as controladorias e ouvidorias de cada órgão têm exercido, de forma descentralizada, a função de controle, acompanhamento e promoção da LAI, o que em muitos casos tem sido fator decisivo para o sucesso da aplicação da Lei (PAES et al., 2017).

Após investigarem a transparência passiva em municípios que possuem ControladoriaGeral, Cruz, Silva e Spinelli (2016) afirmam que sua presença na estrutura organizacional não serve de garantia para a promoção da transparência municipal e para o cumprimento da LAI. No entanto, a existência da controladoria, em municípios acima de 100 mil habitantes, aponta para maior incidência de regulamentação do acesso à informação. $O$ trabalho desempenhado pelas controladorias e ouvidorias, no que se refere ao monitoramento do atendimento dos órgãos aos pedidos de informação, é dificultado por aspectos identificados na pesquisa. São exemplos os casos em que os pedidos não são de competência do órgão que o recebeu ou quando o órgão não possui a informação. Ao esclarecer a situação ao cidadão, os órgãos podem classificar essa resposta como respondida, atendida, negada ou indeferida, dependendo da classificação da discricionariedade do órgão. Observa-se uma limitação no cumprimento da LAI, pois mesmo que os órgãos disponibilizem relatório conforme previsto, os dados fornecidos não poderão ser comparados. Paes, Balbino e Marchezini (2014) observam que nem todos os órgãos utilizam a mesma terminologia para os pedidos indeferidos, alguns optando por incluir aqueles pedidos cuja informação não corresponde a um pedido de informação ou não competem ao órgão que o recebeu.

Além da falta de controle e fiscalização, outro fator que pode estar influenciando a capacidade de transparência passiva dos poderes é a ausência de recursos, sejam esses financeiros, de pessoal ou tecnológicos. Os problemas tecnológicos enfrentados no envio da solicitação, a ausência de sistema eletrônico nos portais e o não retorno aos pedidos são indicativos da falta de recursos empregados para o desenvolvimento da transparência nos poderes. Raupp e Pinho (2015) investigaram a transparência passiva de 79 câmaras de municípios brasileiros com população superior a 300.000 habitantes e também enfrentaram problemas tecnológicos com as plataformas, não sendo possível enviar os pedidos para 11 câmaras. Além disso, 56 câmaras não responderam à solicitação enviada dentro do prazo legal, demonstrando ausência de capacidade em viabilizar a transparência passiva.

$\mathrm{Na}$ análise realizada com os poderes estaduais observou-se relação uma direta entre a estrutura das plataformas e o retorno às solicitações de informação. Os governos de estado, que apresentaram plataformas mais estruturadas, com sistema específico para a solicitação de informações, conforme determinado pela LAI, também receberam a maior taxa de retorno e a maior quantidade de respostas satisfatórias. Por outro lado, as assembleias legislativas apresentaram as piores notas no quesito comunicação na plataforma, indicando que o poder não disponibiliza espaço destinado ao acesso à informação. Tornando mais evidente a relação entre a estrutura das plataformas e a disponibilização de informações de forma passiva, as assembleias legislativas também obtiveram a menor taxa de retorno às solicitações realizadas.

Os resultados encontrados demonstram que o uso das tecnologias de informação e comunicação impulsiona a transparência passiva dos poderes estaduais. Corroboram, portanto, a afirmação de Bertot, Jaeger e Grimes (2010) quanto à capacidade das tecnologias da 
informação e comunicação para promover a transparência e reduzir a corrupção, instigando a responsabilização dos agentes públicos. Com a disponibilização de um sistema eletrônico para acesso à informação, os poderes criam um canal de comunicação com a sociedade, viabilizando uma comunicação mais clara e acessível. Dessa forma, utilizam o potencial das tecnologias da informação e comunicação, destacado por Kakabadse et al. (2003), para reforçar a accountability.

Esse potencial, entretanto, é alcançado em alguns poderes estaduais, que disponibilizam espaço adequado para a realização do pedido de informação e fornecem ao solicitante a informação de forma satisfatória. $\mathrm{O}$ acesso à informação de modo satisfatório foi concedido por 31 dos 81 poderes estaduais analisados, sendo 17 governos de estado, 10 tribunais de justiça e 4 assembleias legislativas. A diferença no avanço da transparência passiva de um poder para outro pode ser observada pela comparação dos principais aspectos restritivos encontrados em cada poder, retratados no Quadro 2.

Quadro 2: Principais aspectos restritivos por poder

\begin{tabular}{|c|l|}
\hline Poderes & \multicolumn{1}{c|}{ Aspectos restritivos } \\
\hline \multirow{3}{*}{ Governos de Estado } & Presença de barreiras nas plataformas \\
\cline { 2 - 3 } & Declaração de ausência da informação solicitada \\
\cline { 2 - 2 } & Respostas incompletas \\
\hline \multirow{3}{*}{ Tribunais de Justiça } & Não recebimento de protocolo ou recibo do envio do pedido \\
\cline { 2 - 2 } & Ausência de resposta \\
\cline { 2 - 2 } & Negativa de acesso à informação \\
\hline \multirow{3}{*}{$\begin{array}{c}\text { Assembleias } \\
\text { Legislativas }\end{array}$} & $\begin{array}{l}\text { Inexistência de espaço destinado ao acesso à informação nos portais } \\
\text { eletrônicos }\end{array}$ \\
\cline { 2 - 2 } & Não recebimento de protocolo ou recibo do envio do pedido \\
\cline { 2 - 2 } & Ausência de resposta \\
\hline
\end{tabular}

Fonte: Dados da pesquisa (2017).

As dificuldades encontradas nos governos de estado indicam que, embora o poder já esteja cumprindo seu dever de transparência passiva, ainda são necessárias adequações em relação aos campos obrigatórios em seus formulários e à completude das informações fornecidas. Nos tribunais de justiça, as barreiras enfrentadas demonstram que são necessárias adequações mais estruturais, principalmente em suas plataformas, para que viabilizem o acompanhamento dos pedidos realizados e também se dedique tratamento diferenciado aos pedidos de informação, aumentando a taxa de retorno. Já nas assembleias legislativa, os principais aspectos restritivos indicam que foram poucas as iniciativas até então tomadas para adequação à LAI, sendo necessário que o poder perceba sua defasagem nesse processo e tome iniciativas para o desenvolvimento de espaços destinados ao acesso à informação em seus portais eletrônicos.

A falta de atendimento às exigências legais de disponibilização de informações à sociedade por meio da transparência passiva observada nas assembleias legislativas é perturbante, pois o poder que elabora a legislação é justamente aquele que menos cumpre. Diferentemente dos outros poderes que demonstram alguns avanços, parece que nas assembleias legislativas ainda predomina a cultura do sigilo, destacada pela CGU (2011) como um dos grandes obstáculos para a abertura dos governos. Os resultados encontrados nesse poder apontam para a necessidade de construção de uma cultura de acesso à informação, mudando o posicionamento perante a sociedade. Da mesma forma, essa mudança cultural também deve ocorrer por parte da sociedade. Quando os cidadãos têm o hábito de monitorar a atuação dos gestores públicos através da solicitação de informações, esses se sentem obrigados a promover a accountability, conforme abordado por Akutsu e Pinho (2002). A participação dos cidadãos, como nas atividades de seleção dos governantes e de vigilância sobre as suas ações, se configura 
elemento-chave da accountability (ROCHA, 2013).

Não há no Brasil uma cultura de acompanhar e fiscalizar os agentes públicos. A implementação de uma legislação que regulamenta o acesso à informação deveria considerar esse contexto, sob risco de ser implementada uma norma que versa sobre uma realidade diferente da qual é aplicada. Ao sancionar a LAI, o Brasil seguiu a tendência mundial de adoção de leis de acesso, como demonstrado por Angélico (2015). A adoção de estruturas de países mais desenvolvidos, sem necessariamente estarem adequadas para a realidade do país em que estão sendo implementadas é, segundo Riggs (1964), uma característica das sociedades prismáticas, como a brasileira. Por conta da dependência das sociedades prismáticas em relação às difratadas, as primeiras são compelidas a implementar as estruturas das últimas (MOTTA; ALCADIPANI, 1999).

A existência do formalismo auxilia na compreensão da realidade brasileira. Uma vez que a lei não condiz com a realidade em que é aplicada, essa discrepância entre a norma legal e a conduta concreta passa a ser institucionalizada. Assim, o não atendimento à legislação passa a ser considerado normal, não havendo estímulo para que os órgãos públicos realizem esforços de adequação aos requisitos de disponibilização de informações à sociedade. Segundo Motta e Alcadipani (1999), o fato de ocorrer desrespeito a algumas leis, dentro de uma sociedade, faz com que haja uma generalização da desconfiança em torno da validade de todas as demais leis daquela sociedade. Por conseguinte, legitima-se na sociedade brasileira a ideia de que algumas leis não precisam necessariamente ser cumpridas (VIEIRA; COSTA; BARBOSA, 1982).

Silva, Eirão e Cavalcante (2015), ao analisarem as leis de acesso à informação dos países da América Latina, afirmam que há várias semelhanças entre as leis adotadas, sendo possível visualizar a influência das mais antigas nas mais recentes. Os autores relatam similaridades na redação dos textos relativas aos critérios de transparência passiva. Entretanto, salientam que a aplicação das leis pode divergir, dependendo da orientação política vigente em cada país. Isso mostra que o aprendizado está sendo lento e penoso, como afirmado por Ramos (1983), para os casos em que se adotam soluções formalísticas, ou seja, quando a lei antecipa as práticas coletivas.

Algumas exigências da LAI ainda não estão sendo cumpridas em determinados poderes da esfera estadual: a garantia do direito de acesso à informação de forma transparente, clara e em linguagem de fácil compreensão (artigo $5^{\circ}$ ); a criação do serviço de informações ao cidadão (artigo $9^{\circ}$, I); a identificação do requerente sem exigências que inviabilizem a solicitação (artigo $10, \S 1^{\circ}$ ); a viabilização pelos órgãos e entidades do poder público de alternativa de encaminhamento de pedidos de acesso por meio de seus sítios oficiais na internet (artigo 10, $\S$ $2^{\circ}$ ); a autorização ou concessão de acesso imediato à informação disponível ou retorno em prazo não superior a 20 dias, prorrogáveis por mais 10 dias (artigo 11); a comunicação de data, local e modo para se realizar a consulta nos casos em que não é possível conceder o acesso (artigo $\left.11, \S 1^{\circ}, \mathrm{I}\right)$; a indicação das razões de fato ou de direito da recusa, total ou parcial, do acesso pretendido (artigo 11, $\S 1^{\circ}$, II); a publicação de relatório estatístico contendo a quantidade de pedidos de informação recebidos, atendidos e indeferidos (artigo 30, III) (BRASIL, 2011).

Os variados graus de atendimento aos dispositivos da LAI são marcantes no estudo empreendido. Enquanto alguns apresentam sistemas tecnológicos mais avançados e que viabilizam o exercício da transparência passiva de forma satisfatória, outros ainda adotam posturas de restrição no acesso à informação, replicadas ao longo de anos. Essas heterogeneidades, juntamente com o formalismo, constituem-se nas principais características da sociedade prismática. Por acumular traços dos modelos concentrado e difratado de Riggs (1964), nela são encontradas ao mesmo tempo o avançado e o atrasado, com mistura de elementos tecnológicos e antigos (RAMOS, 1983).

Mesmo que a adoção da LAI tenha sido uma solução formalística, e que o processo de adaptação seja agora penoso, representa um avanço para a transparência pública brasileira. Essa 
medida foi necessária para que a esfera pública voltasse esforços para a construção de espaços em seus sítios eletrônicos para disponibilização de informações. Em sociedades influenciadas por modelos estrangeiros, como a brasileira, Machado-da-Silva et al. (2003) consideram que a adoção de uma estrutura formal mediante um ato legal ocorre mais facilmente do que a institucionalização do correspondente comportamento social.

\section{Considerações Finais}

$\mathrm{Na}$ esfera estadual, é comum que a sede dos poderes se encontre a centenas de quilômetros de determinados cidadãos. Dada a dificuldade de contato presencial, as plataformas digitais representam uma forma viável de contato entre o poder público e a sociedade civil. Considerando a importância desse canal, esperava-se encontrar plataformas mais estruturadas para a disponibilização de informação mediante solicitação. Além da grande quantidade de poderes que não retornaram ao pedido realizado, preocupa também a alta incidência de portais eletrônicos sem espaço adequado para o cidadão solicitar a informação, o que demonstra a inércia desses poderes na adoção de medidas para viabilizar a transparência passiva.

Observou-se relação direta entre a estrutura das plataformas e o retorno às solicitações. A ausência de recursos tecnológicos nos portais eletrônicos para realização do pedido compromete o exercício da transparência passiva. Todavia, a razão para essa ausência pode ser interpretada muito mais como uma falta de vontade dos atores que representam as instituições públicas, dos funcionários em envidarem esforços para a melhoria da transparência, do que pela indisponibilidade de plataformas de transparência. A CGU disponibiliza a todos os órgãos públicos que aderirem ao Programa Brasil Transparente, o código fonte do sistema eletrônico do Serviço de Informação ao Cidadão, além de apoio técnico na implantação do sistema e treinamento sobre transparência e acesso à informação para os agentes públicos interessados. A tecnologia e a capacitação, portanto, estão à disposição dos poderes estaduais, sendo ainda necessário despertar o interesse daqueles agentes públicos que não cultivam o espírito da accountability. $\mathrm{O}$ potencial de melhoria da transparência passiva observado nos órgãos que aderem ao Programa Brasil Transparente demonstra que a vontade da autoridade do órgão em assinar o termo de adesão pode ser a atitude necessária para início das adequações do poder aos requisitos de transparência passiva.

Decorridos mais de cinco anos de vigência da LAI, nenhum dos três poderes demonstrou estar totalmente adequado aos dispositivos nela previstos. Essa discrepância entre as exigências na legislação e a realidade observada foi explicada pelas lentes do formalismo (RIGGS, 1964). O Brasil, por apresentar características de uma sociedade prismática, tende a adotar iniciativas de países mais desenvolvidos, sem, contudo, apresentar uma realidade condizente com a medida adotada. A busca por melhores práticas e a inspiração em experiências bem-sucedidas em outros países é uma iniciativa a ser valorizada, desde que tomada levando em consideração a realidade brasileira. Assim, na adoção de uma lei de acesso à informação devem-se considerar aspectos que diferenciam o Brasil de países mais desenvolvidos, como a displicência dos agentes públicos com a transparência, a sensação de impunidade com o não cumprimento das legislações e a postura passiva dos cidadãos frente às questões governamentais.

A ausência de transparência passiva nos poderes investigados, com uma situação menos agravante nos governos de estado, revela um quadro desalentador, sem grandes perspectivas de promover a construção de transparência das informações públicas. Ainda que a lei pudesse ser uma justificativa, mesmo já decorridos, em média, 5 anos desde a entrada em vigor até o período de coleta de dados da presente pesquisa, presume-se que o atendimento às exigências legais não seja difícil do ponto de vista técnico, e que os poderes investigados teriam profissionais capacitados e recursos financeiros para tal. O presente trabalho buscou avançar em um tema ainda pouco explorado. Entende-se que os poderes precisam visualizar a situação em que se encontram, para então definir ações de melhoria na disponibilização de informações. Com o 
diagnóstico elaborado nesse estudo, futuros trabalhos poderão avançar para a análise de variáveis que possam estar influenciando os resultados observados. O conhecimento dos fatores que influenciam nos resultados contribuirá para a elaboração de ações que contribuam no desenvolvimento da transparência passiva. Sugere-se também a realização de trabalho que estabeleça parâmetros e pesos para os indicadores avaliados no presente estudo, permitindo a soma dos valores encontrados em cada aspecto avaliado. Nesse sentido, poderiam ser respondidas questões a respeito do peso dos fatores que envolvem a disponibilização de informações ao cidadão, como por exemplo, se seria mais transparente o órgão que disponibiliza a resposta completa fora do prazo previsto na legislação ou aquele que atende o prazo fornecendo acesso parcial à informação solicitada. Dessa forma, o modelo a ser desenvolvido, passível de aplicação em todos os níveis e esferas governamentais, apresentaria o nível de transparência passiva dos órgãos públicos avaliados.

\section{Referências}

ABRUCIO, F. L.; LOUREIRO, M. R. Finanças públicas, democracia e accountability. In: ARVATE, P. R.; BIDERMAN, C. (Org.). Economia do setor público no Brasil. Rio de Janeiro: Elsevier, 2004. p. 75-102.

AKUTSU, L.; PINHO, J. A. G. Sociedade da informação, accountability, e democracia delegada: investigação em portais de governo no Brasil. Revista de Administração Pública, Rio de Janeiro, v. 36, n. 5, p. 723-745, set./out. 2002.

ANGÉLICO, F. Lei de acesso à informação: reforço ao controle democrático. São Paulo: Estúdio Editores.com, 2015.

ANGÉLICO, F.; TEIXEIRA, M. A. C. Acesso à Informação e Ação Comunicativa: Novo Trunfo para a Gestão Social. Desenvolvimento em Questão, v.10, n.21, p.7-27, set./dez. 2012. BARACCHINI, S. A. A inovação presente na administração pública brasileira. Revista de Administração de Empresas, São Paulo, v.42, n.2, p.104-109, abr./jun. 2002.

BERTOT, J. C.; JAEGER, P. T.; GRIMES, J. M. Using ICTs to create a culture of transparency: E-government and social media as openness and anti-corruption tools for societies. Government Information Quarterly, v.27, p. 264-271, 2010.

BRASIL. Constituição da República Federativa do Brasil: promulgada em 5 de Outubro de 1988, 1988.

Lei $\mathbf{n}^{\circ}$ 12.527, de 18 de novembro de 2011. Regula o acesso a informações previsto no inciso XXXIII do art. $5^{\circ}$, no inciso II do $\S 3^{\circ}$ do art. 37 e no $\S 2^{\circ}$ do art. 216 da Constituição Federal; altera a Lei $n^{\circ} 8.112$, de 11 de dezembro de 1990; revoga a Lei $n^{\circ}$ 11.111, de 5 de maio de 2005, e dispositivos da Lei $n^{\circ} 8.159$, de 8 de janeiro de 1991; e dá outras providências. Brasília: Presidência da República, 2011.

Decreto $\mathbf{n}^{\circ}$ 7.724, de 16 de maio de 2012. Regulamenta a Lei no 12.527 , de 18 de novembro de 2011, que dispõe sobre o acesso a informações previsto no inciso XXIII do caput do art. 5ำ, no inciso II do $\S 3^{\circ}-$ do art. 37 e no $\S 2^{\circ}$ do art. 216 da Constituição. Brasília: Presidência da República, 2012.

CAMPAGNONI, M. et al. Transparência no Poder Legislativo Municipal: uma análise dos portais eletrônicos das câmaras de vereadores das capitais brasileiras. Revista Gestão Organizacional, v. 9, n. 1, 2016.

CAMPOS, A. M. Accountability: quando poderemos traduzi-la para o português? Revista de administração pública, v. 24, n. 2, p. 30-50, 1990.

CENEVIVA, R. Accountability: novos fatos e novos argumentos - uma revisão da literatura recente. In: ENCONTRO DE ADMINISTRAÇÃO PÚBLICA E GOVERNANÇA, II, 2006, São Paulo. Anais... Rio de Janeiro: ANPAD, 2006.

CENEVIVA, R.; FARAH, M. F. S. Avaliação, informação e responsabilização no setor público. Revista de Administração Pública, v. 46, n.4, p.993-1016, 2012. 
CONTROLADORIA GERAL DA UNIÃO (CGU). Acesso à informação pública: uma introdução à Lei 12.527, de 18 de novembro de 2011. Brasília: Eclips Design, 2011.

CRUZ, M. C. M. T.; SILVA, T. A. B.; SPINELLI, M. V. O papel das controladorias locais no cumprimento da Lei de Acesso à Informação pelos municípios brasileiros. Cadernos EBAPE.BR, v. 14, n. 3, p. 721, 2016.

FERREIRA, L. B.; TORRECILHA, N.; MACHADO, S. H. S. A técnica de observação em estudos de administração. In: ENCONTRO NACIONAL DOS PROGRAMAS DE PÓSGRADUAÇÃO E PESQUISA EM ADMINISTRAÇÃO, 36., 2012, Rio de Janeiro. Anais... Rio de Janeiro: ANPAD, 2012.

FILGUEIRAS, F. A tolerância à corrupção no Brasil: uma antinomia entre normas morais e prática social. Opinião Pública, v. 15, n. 2, p. 386-421, 2009.

GUERRA, E. M. Os controles externo e interno da administração pública e os tribunais de contas. Belo Horizonte: Fórum, 2003.

JAMBEIRO, O. et al. e-Governo, Participação e Transparência de Gestão. In: Conferência ACORN-REDECOM, V, 2011, Anais... Lima, 2011.

KAKABADSE, A.; KAKABADSE, N.K.; KOUZMIN, A. Reinventing the democratic governance project through information technology? a growing agenda for debate. Public Administration Review, v. 63, n. 1, p. 44-60, 2003.

MACHADO-DA-SILVA, C. L. et al. Institucionalização da mudança na sociedade brasileira: o papel do formalismo. In: In: VIEIRA, M. M. F.; CARVALHO, C. A. (Orgs.).

Organizações, Instituições e Poder no Brasil. Rio de Janeiro: FGV, 2003. p. 179-202. MARIA, J. F. A. Desenho institucional e accountability: pressupostos normativos da teoria minimalista. Revista de Sociologia Política, Curitiba, v. 18, n. 35, p. 27-40, fev. 2010. MICHENER, G.; BERSCH, K. Identifying transparency. Information Polity, v. 18, p. 233242, 2013.

MICHENER, G.; MONCAU, L. F. M.; VELASCO, R. Estado brasileiro e transparência: avaliando a aplicação da Lei de Acesso à Informação. Rio de Janeiro: FGV e Open Society Foundations, 2014.

MOTTA, F. C. P.; ALCAPADINI, R. Jeitinho brasileiro, controle social e competição.

Revista de Administração de Empresas, São Paulo, v. 39, n. 1, p. 6-12, jan./mar. 1999.

O’DONNELL, G. Accountability horizontal e novas poliarquias. Revista Lua Nova, São Paulo, n. 44, p. 27-53, maio, 1998.

OLIVEIRA, A. G.; CARVALHO, H. A.; CORRÊA, D. P. Governança pública e governabilidade: accountability e disclosure possibilitadas pela contabilidade aplicada ao setor público como instrumento de sustentabilidade do Estado. Revista de Educação e Pesquisa em Contabilidade, v. 7, n. 1, p. 91-104, 2013.

PADILHA, H.; MICHENER, G.; CONTRERAS, E. Avaliando a aplicação da lei de acesso nos estados e nas grandes cidades. In: MICHENER, G. (Org.). Transparência local no Brasil: avaliando a aplicação da Lei de Acesso nos estados e nas grandes cidades. Rio de Janeiro: FGV e Open Society Foundations, 2016.

PAES, B.; BALBINO, F.; MARCHEZINI, J. Monitoramento da Lei de Acesso à

Informação Pública em 2014. São Paulo: Article 19 e Open Society Foundations, 2014. PAES, B. et al. Os 5 anos da Lei de Acesso à Informação: uma análise de casos de transparência. São Paulo: Article 19 e Open Society Foundations, 2017.

PEREIRA, J. M. Reforma do Estado e transparência: estratégias de controle da corrupção no Brasil. In: CONGRESO INTERNACIONAL DEL CLAD SOBRE LA REFORMA DEL ESTADO Y DE LA ADMINISTRACIÓN PÚBLICA, VII, 2002, Lisboa, Portugal. Anais... CLAD, 2002.

PINHO, J. A. G.; SACRAMENTO, A. R. Accountability: já podemos traduzi-la para o português? Revista de Administração Pública, v. 43, n. 6, p.1343-1368, nov./dez. 2009. 
PLATT NETO, O. et al. Publicidade e transparência das contas públicas: obrigatoriedade e abrangência desses princípios na administração pública brasileira. Contabilidade Vista \& Revista, v. 18, n. 1, p. 75-94, 2007.

RAMOS, A. G. Administração e contexto brasileiro: esboço de uma teoria geral da administração. Rio de Janeiro: FGV, 1983.

RAUPP, F. M; PINHO, J. A. G. Os Vereadores Prestam Contas em Portais Eletrônicos? Um Estudo Comparativo entre Municípios do Estado da Bahia e de Santa Catarina.

Administração Pública e Gestão Social, v.5, n.3, jul./set. 2013.

RAUPP, F. M.; PINHO, J. A. G. A Lei, ora a Lei: um Balanço da (In)Transparência Passiva em Câmaras Municipais Brasileiras. In: ENCONTRO DE ADMINISTRAÇÃO DA INFORMAÇÃO - EnADI, V, 2015, Brasília. Anais... Rio de Janeiro: ANPAD, 2015. RIGGS, F. W. A ecologia da administração pública. Rio de Janeiro: FGV, 1964.

ROCHA, A. C. Accountability: constituinte necessária das sociedades democráticas. Revista da Faculdade de Administração e Economia, São Paulo, v. 5, n. 1, p. 81-100, 2013.

SILVA, T. E.; EIRÃO, T. G.; CAVALCANTE, R. S. Relacionando la legislación sobre acceso a laInformación de los países del MERCOSUR. Biblios: Journal of Librarianship and Information Science, n. 56, p. 28-38, 2015.

SLOMSKI, V. Controladoria e governança na gestão pública. 1. ed. São Paulo: Atlas, 2012.

VIEIRA, J. B.; CALDAS, R. W. The impact of public transparency in fighting corruption. In: CeDEM 12 Conference for E-Democracy and Open Government, Austria. Univ. Krems, 2012.

VIEIRA, C. A.; COSTA, F. L.; BARBOSA, L. O. O "jeitinho" brasileiro como um recurso de poder. Revista de Administração Pública, v. 16, n. 2, p. 5-31, 1982.

WARMLING, N. N.; BERNARDES, M. B.; SANTOS, P. M. A lei de acesso à informação e o dever de transparência: uma análise do exercício da transparência passiva no âmbito dos Tribunais de Justiça brasileiros. In: ROVER, A. J.; SANTOS, P. M.; MEZZAROBA, O. (Org.). Governo eletrônico e inclusão digital. Florianópolis: Conceito Editorial 2014. P. 63 81.

YAZIGI, A. F. Dinero, política y transparencia: el imperativo democrático de combatir la corrupción. In: INTERNATIONAL ANTI-CORRUPTION CONFERENCE (IACC), $9^{\text {th }}$, 1999, Durban, África do Sul. Durban: IACC, 1999.

ZUCCOLOTTO, R.; TEIXEIRA, M. A. C.; RICCIO, E. L. Transparência: reposicionando o debate. Revista Contemporânea de Contabilidade, v. 12, n. 25, p. 137-158, 2015. 
Tabela 2: Tipo e tempo de resposta por órgão e estados analisados

\begin{tabular}{|c|c|c|c|c|c|c|}
\hline \multirow[b]{2}{*}{ Estados } & \multicolumn{2}{|c|}{ Governos de Estados } & \multicolumn{2}{|c|}{ Assembleias Legislativas } & \multicolumn{2}{|c|}{ Tribunais de Justiça } \\
\hline & Tipo de resposta & $\begin{array}{c}\text { Tempo de resposta } \\
\text { (dias) }\end{array}$ & Tipo de resposta & $\begin{array}{c}\text { Tempo de } \\
\text { resposta (dias) }\end{array}$ & Tipo de resposta & $\begin{array}{c}\text { Tempo de } \\
\text { resposta (dias) }\end{array}$ \\
\hline Acre & Acesso integral & 20 & Sem resposta & - & Não possui a informação & 3 \\
\hline Alagoas & Sem resposta & 21 & Sem resposta & - & Acesso negado & 2 \\
\hline Amapá & - & - & Sem resposta & - & Acesso integral & 1 \\
\hline Amazonas & Acesso integral & 2 & Sem resposta & - & Sem resposta & - \\
\hline Bahia & - & - & - & - & Sem resposta & - \\
\hline Ceará & Acesso integral & 20 & Sem resposta & - & Acesso negado & 5 \\
\hline Distrito Federal & Acesso integral & 13 & Acesso integral & 8 & - & - \\
\hline Espírito Santo & Acesso integral & 1 & Acesso integral & 12 & Acesso integral & 18 \\
\hline Goiás & Acesso integral & 1 & Sem resposta & - & Sem resposta & - \\
\hline Maranhão & Acesso parcial & 2 & Sem resposta & - & Sem resposta & - \\
\hline Mato Grosso & Acesso integral & 0 & Sem resposta & 26 & Acesso integral & 2 \\
\hline Mato Grosso do Sul & Acesso integral & 13 & Sem resposta & - & Sem resposta & - \\
\hline Minas Gerais & Acesso integral & 16 & Sem resposta & - & Sem resposta & - \\
\hline Pará & Sem resposta & 41 & Sem resposta & - & Sem resposta & - \\
\hline Paraíba & Acesso integral & 7 & Sem resposta & - & Sem resposta & - \\
\hline Paraná & Acesso parcial & 29 & Sem resposta & - & Sem resposta & - \\
\hline Pernambuco & Acesso integral & 19 & Acesso integral & 4 & Acesso integral & 1 \\
\hline Piauí & Acesso integral & 5 & Sem resposta & - & Sem resposta & - \\
\hline Rio de Janeiro & Não possui a informação & 1 & Acesso negado & 10 & Acesso negado & 14 \\
\hline Rio Grande do Norte & Acesso integral & 0 & Sem resposta & - & Sem resposta & - \\
\hline Rio Grande do Sul & Acesso integral & 1 & Acesso parcial & 3 & Acesso parcial & 0 \\
\hline Rondônia & Acesso integral & 18 & Sem resposta & - & Acesso parcial & 2 \\
\hline Roraima & Acesso parcial & 7 & Sem resposta & - & - & - \\
\hline Santa Catarina & Acesso parcial & 0 & Sem resposta & - & Acesso integral & 0 \\
\hline São Paulo & Acesso integral & 10 & Sem resposta & - & Acesso integral & 15 \\
\hline Sergipe & Acesso parcial & 7 & - & - & Acesso integral & 0 \\
\hline Tocantins & Acesso parcial & 10 & Sem resposta & - & Acesso integral & 1 \\
\hline
\end{tabular}

Fonte: Dados da pesquisa (2017).

Nota: A resposta às solicitações enviadas estão na coluna "Tipo de resposta", e na coluna "Tempo de resposta" informamos o tempo apenas das solicitações respondidas. Sobre os rótulos: "Sem resposta" indica que o órgão não respondeu à solicitação, "Acesso negado" indica que a resposta foi enviada, mas o órgão se negou a dar a informação e não justificou", "Não possui a informação" é a justificativa dada pelo órgão para não fornecer a informação, "Acesso integral" indica que a informação fornecida responde ao que foi perguntado, e "Acesso parcial" indica que a responde fornecida não contempla por completo o que foi perguntado. O tempo em dias quando "0" indica que a resposta se deu no mesmo dia do envio. 